\title{
El Feed Infinito: \\ El potencial del webcómic en la máquina de memes \\ Irene Gil Giménez
}

Recibido: 15.09.2021 — Aceptado: 12.10.2021

\section{Titre / Title / Titolo}

Le flux infini: le potentiel des webcomics dans la machine à mèmes The infinite feed: the potential of webcomics in the meme machine Il feed infinito: il potenziale dei webcomics nella macchina dei meme

\section{Resumen / Résumé / Abstract / Riassunto}

A finales del siglo XX y principios del XXI, el webcómic se desarrolló de forma independiente al mercado editorial mediante productos diseñados específicamente para ser leídos online. El medio digital se configuró como un espacio único y revolucionario para la explotación de nuevas vías dentro del cómic, tal y como auguraban autores como Scott McCloud. No obstante, el fenómeno más popular ligado a las viñetas online ha acabado siendo el «meme», lejos de conceptos como el lienzo infinito y más cerca del debate sobre la reproductibilidad técnica de la imagen o la creación colectiva. De existir en rincones muy especializados de la red a recibir millones de interacciones en redes sociales, el webcómic se ha convertido en un fenómeno, pero no el que sus pioneros esperaban. El objetivo de este texto es analizar las características expresivas y narrativas intrínsecas del cómic digital que lo han convertido en el objeto viral por excelencia.

A la fin du XX siècle et au début du XX, le webcomic s'est développé indépendamment au marché de l'édition grâce à des produits spécialement conçus pour être lus en ligne. Le support numérique a été configuré comme un espace unique et révolutionnaire pour l'exploitation de nouvelles avenues au sein de la bande dessinée, comme prédit par des auteurs tels que Scott McCloud. Ne pas Cependant, le phénomène le plus populaire lié aux vignettes en ligne a fini par être la «mème», loin des concepts tels que la toile infinie et plus proche du débat sur la reproductibilité technique de l'image ou de la création collective. De l'existence dans des coins hautement spécialisés du réseau à la réception de millions d'interactions dans réseaux sociaux, le webcomic est devenu un phénomène, mais pas celui que ses pionniers ils attendaient. L'objectif de ce texte est d'analyser les caractéristiques expressives et narratives intrinsèques à la bande dessinée numérique qui en a fait l'objet viral par excellence.

At the end of the 20th century and the beginning of the 21 st, the webcomic developed independently from the publishing market through products specifically designed to be read online. The digital medium was configured as a unique and revolutionary space for the exploitation of new avenues within the comic, as predicted by authors such as Scott McCloud. However, the most popular phenomenon linked to online vignettes has ended up being the «meme», away from concepts such as the infinite canvas and closer to the debate on the technical reproducibility of the image or collective creation. It has changed, away from an existence in highly specialized corners of the network, it now receives millions of interactions in social networks; the webcomic has become a phenomenon, but not the one that its pioneers expected. The objective of this text is to analyze the expressive and narrative characteristics intrinsic to digital comics that have made it nowadays's viral object par excellence.

Alla fine del secolo XX e all'inizio del XXI, il webcomic si è sviluppato in modo indipendente dal mercato editoriale attraverso prodotti studiati appositamente per essere letti online. Il mezzo digitale si è configurato come uno spazio unico e rivoluzionario per lo sfruttamento di nuove strade all'interno del fumetto, come previsto da autori come Scott McCloud. Tuttavia, il fenomeno più popolare legato alle vignette online ha finito per essere il «meme», lontano da concetti come la tela infinita e più vicino al dibattito sulla riproducibilità tecnica dell’immagine o creazione collettiva. Dall'esistenza in angoli altamente specializzati della rete alla ricezione di milioni di interazioni in social network, il webcomic è diventato un fenomeno, ma non quello che i suoi pionieri si aspettavano. L'obiettivo di questo testo è analizzare le caratteristiche espressive e narrative intrinseche del fumetto digitale che ne ha fatto l'oggetto virale per eccellenza.

\section{Palabras clave / Mots-clé / Key words I Parole chiave}

Cómic, Webcómic, Internet, Memes, Cultura.

Bande dessinée, Webcomic, Internet, Mèmes, Culture.

Comic, Webcomic, Internet, Memes, Culture.

Fumetti, Webcomic, Internet, Memes, Cultura. 


\section{Introducción}

El webcómic se empieza a configurar a finales de los años 90, heredero por un lado de las tiras de cómic independiente y autobiográficas de periódicos universitarios y de la tradición del Net-Art por otro. La consolidación de los navegadores y del entorno web favoreció la creación de comunidades alrededor de estos artefactos cuyo potencial artístico dependía en igual medida de la habilidad de sus autores como de las innovaciones tecnológicas del entorno. Divulgadores como Scott McCloud pronto proyectaron sobre este nuevo medio una serie de características destinadas a «revolucionan» el lenguaje de los cómics. No todas ellas estaban ligadas a la creación artística, algunas aludían a una relación entre autor y lector que hasta ese momento no tenía precedente. La interactividad que el entorno digital prometía hoy se puede analizar con cierto escepticismo: los agregadores de contenido no siempre han sido beneficiosos para los autores, viéndose obligados a abandonar las comunidades especializadas o los sitios web propios a cambio de conseguir visibilidad en redes sociales. Al mismo tiempo, estas redes sociales evolucionaban construidas sobre un monopolio empresarial en el que el contenido depende de un algoritmo que puede convertirlo en «viral» o volverlo irrastreable. Este texto tiene por objetivo reflexionar sobre las condiciones actuales en las que se encuentra el webcómic y la complicada relación que ha establecido con los llamados «memes», ¿todavía hay espacio para la revolución artística? ¿o solo queda contagiarse y dejarse arrastrar por la corriente vírica?

El enfoque metodológico de este texto se ha articulado a partir del trabajo de Limor Shifman para localizar los elementos que configuran un meme de Internet. Estos elementos se han aplicado sobre el orden semiótico propuesto por Gasca y Gubern para definir aquellos que conforman el discurso del cómic con el objetivo de ver de forma más clara las características que facilitan la «memetización» de su lenguaje. Por otro lado, la información referente a la historia de los webcómics bebe del trabajo de Shaenon Garrity y T. Campbell, la cual se complementa con la obra de Glaser sobre la recepción memética. Por último, a lo largo del texto se reflexiona sobre cómo ha influido sobre el webcómic la popularidad de los memes con el fin de determinar hasta qué punto puede haber sido despojado de las pretensiones artísticas que se proyectaron sobre él en sus primeros años de vida. Este enfoque estético se articula con la obra de Scott McCloud y se complementa con algunos datos cuantitativos que permiten analizar este impacto, tales como las nominaciones a los Eisner, el alcance de los webcómics en redes sociales o sus cifras de venta. La definición de webcómic a la que se ceñirá este texto es la propuesta por Kukkonen (521): «los webcómics son cómics principalmente publicados y distribuidos a través de internet que en ocasiones hacen uso de las posibilidades del medio digital». Esta definición permite diferenciar el artefacto del webcómic de los cómics en papel digitalizados para ser leídos a través de esta vía, pero también le atribuye unas características intrínsecas a su condición digital, ampliamente tratadas por Wilde.

\section{Estado de la cuestión del meme}

El término «meme» fue acuñado por el biólogo Richard Dawkins a raíz de la publicación de su libro El gen egoísta (1976). Si bien no se refiere explícitamente a las conocidas imágenes de Internet en concreto, sino a una serie de artefactos que se trasmiten de una persona a otra a través de la imitación y la apropiación. Para Dawkins, esto pueden ser «melodías, ideas, frases hechas, moda, formas de hacer tazas o de construir arcos» (Knobel y Lankshear: 201). Como plantea Milner (9), durante los años 2000 el término traspasó la frontera de la biología y entró en el campo del estudio de las ciencias sociales y las humanidades. Una vez allí, las definiciones varían según el autor: Knobel y Lankshear (202) definen el meme como «la difusión rápida de una idea concreta materializada en un texto, imagen, lenguaje, movimiento o cualquier otro tipo de artefacto cultural». Por otro lado, el sitio web Know Your Meme explica que estos son «información e ideas que pasan de una persona a otra, cambiando y evolu- 
cionando por el camino». Milner (11) añadiría que los memes «tal y como se usan en las redes de cultura participativa mediada, son artefactos multimodales en los que imagen y texto se integran para contar un chiste, hacer una observación o plantear un argumento».

Crear un meme es fácil y gratis, actualmente existen numerosas herramientas y generadores con plantillas (Meme Generator, Ragemaker.com...) que permiten la creación de estos artefactos sin que sea necesario que el usuario sepa utilizar un software de edición como Photoshop. Muchos de estos artefactos nacen en comunidades que comparten lenguaje y cultura, tales como 4chan, Reddit o Tumblr, pero son susceptibles de difundirse a lo largo de toda la web. La mayoría de los memes más populares son imágenes, pero pueden ser vídeos o happenings. A pesar de que la literatura sobre memes ha proliferado en los últimos años y hay numerosos enfoques respecto a su utilidad, este texto se ciñe al marco que propone Limor Shifman para su estudio.

Para Shifman (20), la principal característica del meme (y lo que lo diferencia del contenido meramente viral), es la capacidad de ser versionado a partir del contenido original mediante el remix y la mimética. El término meme, explica, «es suficientemente flexible para capturar todo el rango de intenciones y acciones comunicativas, las cuales van desde la copia inocente a la imitación con sorna» (21). Para este texto su trabajo resulta imprescindible ya que es su división y subdivisión de los elementos que configuran el meme la que permite observar las características que comparten con algunos de los webcómics más populares en las redes.

La autora propone, partiendo de esta premisa en la que la imitación es imprescindible, tres dimensiones potencialmente imitables que articulan al meme y que forman parte de su propia definición: contenido, forma y posicionamiento $^{1}$. En el tema que concierne a este ensayo la similitud del contenido y la forma entre webcómics y memes es evidente: ambos comparten elementos fácilmente identificables (viñetas, tiras cómicas, bocadillos, encuadres...). Es la dimensión del posicionamiento, que

La traducción es propia, los términos originales que usa la autora son content, form and stance. se divide a su vez en tres subdimensiones: participación, matiz y funciones comunicativas, la que resulta menos obvia y por tanto, quizá más interesante.

Los memes, pues, son un grupo de «objetos digitales» que no solo comparten estas características, sino que se crean con la conciencia de que otros existen y que estos han circulado por la red y han sido imitados y transformados. Este matiz en la definición establece una capa sobre el meme que es vital para diferenciarlo de los virales. El viral «constituye una única unidad cultural (un video, foto o un chiste) que se propaga, un meme siempre es una colección de textos (...). Un vídeo en solitario no es un meme, sino parte de un meme» (Shifman, 56).

Dentro de esa conciencia sobre la existencia del resto de artefactos que componen un meme y la cultura digital que da luz a los fenómenos virales, encontramos un marco cultural propio al que es necesario pertenecer para poder participar:

con los memes la alfabetización digital no es suficiente. Requiere también una alfabetización subcultural: la habilidad de leer y escribir en un lenguaje socialmente aceptado por el nativo subcultural (Milner, 107).

En definitiva, debe entenderse el meme no como un artefacto independiente, sino un conjunto de ellos cuya agregación da forma a un concepto alumbrado en las redes de cultura participativa mediada. Para comprender un meme no basta con haber visto un único vídeo o foto, hay que estar embebido en una cultura digital vernacular e intertextual ${ }^{2}$ que tiende a excluir a aquellos que «están fuera» $\mathrm{o}$ «no lo entienden».

\section{La primera piedra}

El webcómic le debe su nacimiento a la confluencia de dos ámbitos: el cómic y la tecnología. El estado de ambos durante los años 90 propiciaría el caldo de cultivo

\footnotetext{
En el caso de los memes de Internet, estos «operan procesos de reproducción, transformación o recuperación de estructuras provenientes de otros sitios» (Cruz, Pinto y López). Los memes de Internet pueden hacer referencia a otros memes, sucesos de actualidad, eventos históricos, programas de televisión, canciones, películas, cómics y un largo etcétera.
} 
de la proliferación de los cómics online. Por un lado, la combinación de tres nombres que contextualizan el momento que vivía la tecnología: Vannevar Bush, J.C.R. Licklikder e Ivan Sutherland. A grandes rasgos se destacan tres ideas. Vannevar Bush concibió el memex, una librería a cuyo contenido se podría acceder mediante unos vínculos. J.C.R. Licklider visualizó una red mediante la que los ordenadores estarían conectados entre sí. Y, por último, Ivan Sutherland desarrolla la posibilidad de convertir los datos en gráficos. ( $T$. Campbell).

La llegada de USENET a partir de la estructura de ARPANET en 1980 permitió las primeras conexiones entre ordenadores, aunque aún limitada a comunidades universitarias. En ese sistema comienza a alojarse uno de los primeros webcómics: Where the Buffalo Roam (Hans Bjordahl, 1992). Otras propuestas surgieron en entornos parecidos dominados por el índice jerárquico como Slugs (Dominic White, 1992), alojado en Gopher. El asentamiento de Mosaic como navegador alrededor de 1993 representaría las tres revoluciones del párrafo anterior juntas: ordenadores conectados y con la capacidad de acceder a una librería de imágenes. El lienzo estaba preparado para volverse infinito, aunque todavía hubiera que esperar un buen rato hasta que terminara de cargarse.

A finales de los años 80 y principios de los 90, para ser un usuario de internet había que ser aficionado a la tecnología de forma casi imprescindible, dada la complejidad de las interfaces. Como muestra, algunos de los webcómics más populares publicados durante los años 90 giraban alrededor de la cultura geek: Melonpool (Steve
Troop 1996) User Friendly (A.J. Garret 1997) o Penny Arcade (Hopkins y Krahulik 1998).

El público potencial de este medio propició la creación de títulos que compartían formato: tiras al estilo de los periódicos protagonizadas por chicos de clase media, generalmente universitarios y con unas aficiones alrededor de la tecnología, los videojuegos, la fantasía y la ciencia ficción (Garrity). También se daban variaciones de esta estructura a la que se añadían elementos de aventuras y sobrenaturales, con ejemplos como College Roomies from Hell! (Maritza Campos, 1999) o Narbonic (Garrity, 2000). La proliferación de estos webcómics sirvió como impulso para que cómics en papel de la misma temática comenzaran a publicarse en Internet. Este fue el caso de Dilbert, la primera tira sindicada publicada online. El cómic de Scott Adams se convirtió en una de las tiras más populares y con mayor distribución en periódicos de los últimos 25 años (Gallo).

La búsqueda de la identificación con lector se remonta hasta estas primeras tiras publicadas en internet y que apelaban a un público muy específico (habitantes de un lugar concreto, libreros, informáticos...) para que sintieran una relación directa con el contenido y se animaran a visitarlo, aunque no fueran lectores habituales de cómic. Scott McCloud usaría su eterna metáfora sobre los golfistas para justificar este fenómeno: no es necesario hacer algo que le guste a todo el mundo, sino hacer algo que sabes que le va a gustar a alguien y hacerle saber que está ahí y que puede acceder a él (Adventures into digital comics 00:41:32)

Durante los siguientes años, los webcómics vivirían una explosión de formatos y géneros, motivado en parte por el lanzamiento del libro de Scott McCloud La

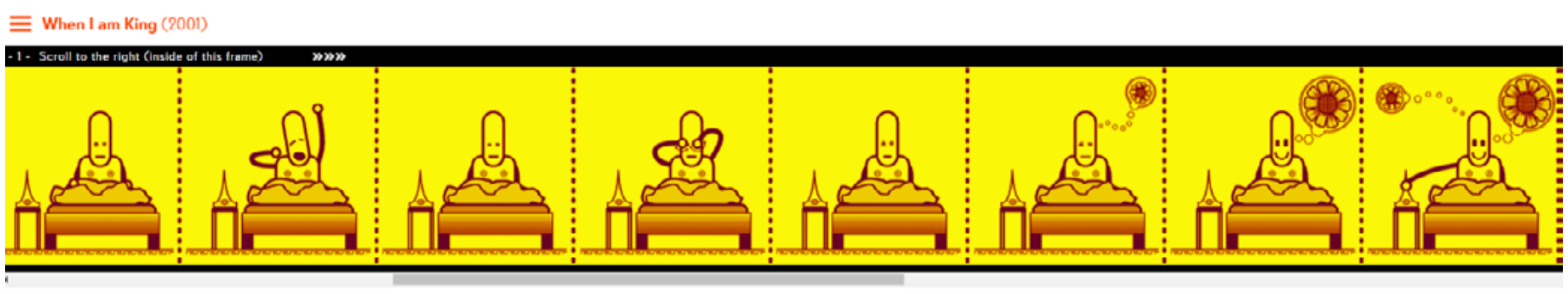

Captura de la interfaz de scroll horizontal de When I Am King 
revolución de los cómics en el año 2000, que hizo que los autores comenzaran a ser conscientes del potencial del producto que estaban creando. No se trataba sólo de la experimentación formal (Zabel), cuyo otro de sus mayores ejemplos fue When I am King, de Demian5 en 2001, sino sobre la diversidad que se abría paso entre los webcómics y que lo había tenido mucho más difícil en el mundo impreso, tanto por su temática como por la falta de recursos de sus autores. Estas circunstancias llevarían a Nowhere Girl a estar nominado a un premio Eisner en 2003, antes de que apareciera la categoría específica para los webcómics en 2005 (Yarbrough).

Este fenómeno es análogo al ocurrido en el cómic underground occidental a partir de los años 60. La creación de obras libres de los filtros editoriales convencionales dio lugar a trabajos más rompedores, en muchos casos dirigidos a públicos habitualmente marginados por la lógica de mercado y que tenían en estas obras alternativas un espacio propio en el que hablar de sus propias problemáticas e inquietudes. Estos espacios propiciaron la creación de populares cómics autobiográficos como Binky Brown Meets the Holy Virgin Mary o las obras del colectivo Wimmen in Comix. La tendencia permeó al cómic independiente, dónde también encontró su representación el retrato de las comunidades LGTB por parte de autoras como Alison Bechdel (M. E. Campbell) o la ciencia ficción «dura» publicada en la revista francesa Metal Hurlant (Frattini y Palmer, 140)

Estas mismas tramas son fáciles de identificar en algunos de los webcómics más populares. Es el caso de Venus Enyy (Erin Lindsey, 2001), Questionable Content (Jeph Jacques, 2003) o Menage a Trois (Gisele Lagacé, 2008) en el tema de la diversidad sexual. O de Tracy White y su Traced (1996), el cual intentaba conectar con otros adolescentes con problemas mentales con el objetivo de que estos no se sintieran solos. También hay obras con una importante carga política y racial que aprovechan las innovaciones artísticas del medio para ofrecer un relato más expresivo. Este es el ejemplo de Spiders (Patrick Farley, 2002), Berlins Favela (Julia Severiens, 2014) o de algunos de los nomina-

Imagen: Demian5. When I am King, 2001. dos a los premios Eisner de 2020, como Cabramatta (Matt Hyunh, 2019) o Who gets called an «unfits mother? (Miriam Libicki, 2019). Otros como XKDC (Randall Munroe, 2005) se han popularizado por sus tiras cómicas tradicionales, pero también por su labor en la divulgación científica y la experimentación formal. Es probable que uno de los ejemplos más famosos de webcómics sea su obra Click \& Drag (2012), una página de una única viñeta de 165888 x 79872 píxeles en la que el lector debe pinchar y arrastrar para poder desplazarse por ella.

Paula Sibila en La intimidad como espectáculo se preguntaba:

¿Qué implica este súbito enaltecimiento de lo pequeño y de lo ordinario, de lo cotidiano y de la gente común? (...) ¿Qué significa esta repentina exaltación de lo banal, esta especie de satisfacción al constatar la mediocridad propia y ajena?» (Sibila 12).

A pesar de las posibilidades artísticas y temáticas del medio digital, los ejemplos de webcómics populares inspirados en el slice-of-life y la auto-parodia son una lista muy familiar para cualquier habitual en las redes sociales: Hyperbole and a half (Allie Brosch, 2009), Sarah's Scribbles (Sarah Andersen, 2011) o Owl Turd Comix (Shen, 2013). Este fenómeno se puede encontrar más allá de las tiras compartidas millones de veces en Facebook, Twitter o Instagram: en los foros de internet, caldos de cultivo del meme, se estaba gestando una subcultura cuya bandera sería precisamente la exaltación de la mediocridad como factor diferenciador (Shifman, 77).

\section{Rage-cómics, macros y el feed infinito}

Los rage-cómics son uno de los mejores ejemplos del uso de los convencionalismos del cómic aplicados a los memes, pero ni remotamente el único: los macros o los «verticales» también comparten las técnicas narrativas para articular su discurso a partir del punch y la yuxtaposición de imágenes que se leen en formato secuencial, así como el uso de una iconografía común (onomatopeyas, rótulos, bocadillos...). No obstante, el uso de las 
representaciones pictóricas de los estereotipos resulta especialmente llamativa, en tanto su dimensión memética permite al lector incrustarse dentro del texto bajo el amparo de la creación colectiva. No mediante una identificación con el contenido en el sentido de lectura tradicional, sino con la inclusión de su propio personaje sobre la plantilla. El «tú» al que Milner hace referencia y que ya no necesita ser pasivo, sino que puede participar en la creación: «se reduce el espacio que diferencia a los que producen el contenido y los que lo consumen» (Milner, 2)

El nacimiento de los rage-cómics se atribuye a la aparición de una tira en el popular foro 4chan en 2007 (Luiz 4). El personaje del rageguy comenzó a utilizarse fuera del contexto de su cómic y en 2008 se introdujo la plantilla de cuatro viñetas que finalizaba siempre con el mismo punch: la imagen del rageguy (Imagen 0). Para entender esta imagen no solo es necesario conocer la estructura de una tira cómica y la posición y función del punch, sino también el estereotipo al que el rageguy representa, el cual se convierte en un signo de un sentimiento con el que el lector lo asocia. El rostro del rageguy sería el primero de una larga lista de estereotipos utilizados en este tipo de cómics, al que se le unen otros como forever alone, challenge accepted, cereal guy, troll face o not bad. Como plantea Shifman (173) «en lugar de decir 'he tenido una mala cita y me siento solo y miserable' puedes pegar el personaje de 'forever alone'».

Los orígenes de la atribución del significado a estas imágenes son difusos, ya que como plantea Milner (103), las características de los memes son el resultado de un proceso social, y es el consenso colectivo de la comunidad el que define la esencia del personaje. Precisamente esta idea de creación colectiva es la que más favorece el gatekeeping sobre el contenido. Los usuarios establecen la diferencia entre utilizar «bien» $\mathrm{o}$ «mal» los memes, obligando a aquel que quiera participar en la creación a demostrar cierta «competencia social» (Milner, 106). Curiosamente, este fenómeno crea un conflicto con los usuarios de estas comunidades, que no ven con buenos ojos cuando sus creaciones saltan al

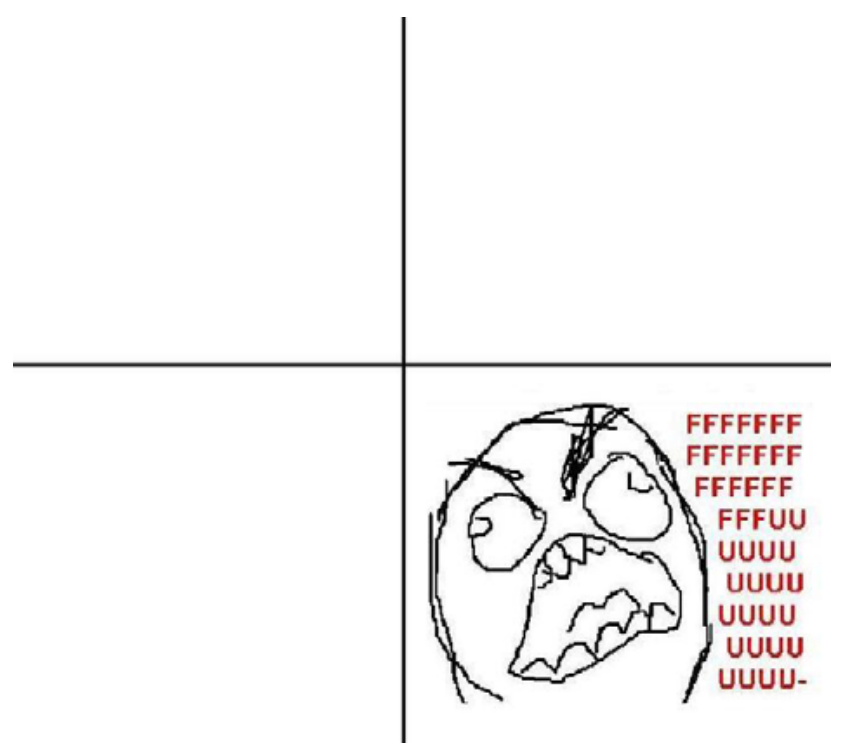

Imagen 0

mundo de los «normies» (una fatídica consecuencia que Angela Nagle trata ampliamente en su obra). ${ }^{4}$

Las características intrínsecas de algunos géneros de memes forman parte de «un lenguaje visual común» compartido con los webcómics, aunque a priori se perciban como dos cosas diferentes (Noding, 2020). Es el caso del uso de los estereotipos en la creación de estas rage-faces. Gasca y Gubern (27) definen el estereotipo como «una imagen o idea simplificada, estable y ritualizada, de amplia aceptación social». Los estereotipos se relacionan generalmente con la idea que una persona se hace de otra, pero como estos autores indican, el estereotipo en ocasiones va más allá de la apariencia física y «se catalogan también formas muy estereotipadas para representar vivencias y estados de ánimo» (27). No solo se consideran estereotipos la forma de representar a un héroe, un villano, un jugador de videojuegos o un estudiante universitario sino cómo se representa la soledad, el enfado o el asombro.

Precisamente esta capacidad para identificarse con un sentimiento es lo que convierte la viñeta del cómic en un potencial meme. Y los webcómics, al contrario

\footnotetext{
4 Nagle, Angela. Muerte a los normies: las guerras culturales en internet que han dado lugar al ascenso de Trump y la alt-right. Tarragona: Orciny Press, 2018
} 
que los rage-comics, no nacen necesariamente en un contexto de creación colectiva, sino que son viralizados y modificados una vez se naturaliza para el lector que esta es una herramienta legítima para cualquier contenido que consuma, como se tratará más adelante.

\section{Abandonando las comunidades: larga vida al algoritmo}

En 2011, Shaenon Garrity, veterana en el mundo de los webcómics, predijo el vuelco que daría la situación: «Los webcómics ya se están convirtiendo en memes. Los más populares son aquellos que pueden salir de su contexto hacia otro, saltando de formato en formato». Si bien a principios de los años 2000 era habitual que los webcómics se desarrollaran en torno a comunidades de hosting como Big Panda, Keenspot, Modern Tales, Tapastic, o Subcultura en España, la popularidad de las redes sociales propició el traslado. Cuando los cómics se desarrollaban en una comunidad estaban ligados los unos a los otros, especialmente cuando en estas había foros, sección de comentarios o eventos; al formar parte de la misma web resultaban naturales los enlaces entre unos y otros.

La interactividad que ofrecen los vínculos en un portal de alojamiento recuerda al símil que hace Casacuberta (45) en el que apunta que navegar también es estar frente a una biblioteca, coger un libro de un estante, hojearlo, dejarlo y coger otro. Las nuevas interfaces de las redes sociales, no obstante, no invitan al usuario a abandonarlas para consultar otra cosa, sino a sumergirse en ellas de forma interminable (Alter). Si Scott McCloud proponía el uso del lienzo infinito, lo que ha llegado a nuestros días ha sido una especie de feed infinito: una sucesión que nunca acaba de contenido seleccionado por un algoritmo en base a los intereses y el historial de navegación del usuario y de todos aquellos con los que interactúa.

En este aspecto, Gabriela Samela hace un análisis del funcionamiento de los agregadores de contenido y cuestiona su transparencia. Por ejemplo, en el caso de Facebook: «la ponderación de estos criterios no es abierta (...) al tiempo que se cruza con criterios no conocidos, como los acuerdos comerciales» (2). La autora argumenta que estas dinámicas poco o nada tienen que ver con la «descentralización»y «democratización»de la «aldea global» y el poder que tendría el usuario de Internet, ya que la interacción, producción y consumo de los contenidos digitales se ve sujeto a unos modelos hegemónicos que concentran el poder a través de un único portal (Google) cuyos criterios de indización son opacos (8) y tienden a favorecer a páginas grandes frente a sitios pequeños (6).

Esta fue precisamente, hace 20 años, una de las críticas más agresivas a las que Scott McCloud tuvo que enfrentarse. En abril de 2001, Gary Groth (editor jefe de The Comics Journal) escribió una dura reseña contra Reinventing Comics, publicado el año anterior. Entre otras cosas, Groth acusaba a McCloud de haberse convertido en «el portavoz de las grandes empresas» al proyectar con su libro una visión demasiado optimista de Internet, ya dominada en ese momento por grandes conglomerados. Para Groth, las teorías de McCloud operaban en la misma lógica neoliberal que la de las empresas y hacían un flaco favor a cualquier movimiento revolucionario, muy lejos del paraíso para el pequeño creador independiente que el divulgador planteaba (Groth).

En este contexto, los webcómics abandonan las comunidades: «En lugar de colaborar nos estamos descentralizando, dispersándonos en las redes sociales. Ya no somos colectivistas (...), ni siquiera necesitan una página web» (Garrity, One of those things). Progresivamente, los géneros más populares en los webcómics dejan de ser aquellos que experimentan formalmente o que tienen argumentos largos y complejos en favor de las tiras cómicas y autoconclusivas que pueden compartirse fácilmente y beneficiarse de las dinámicas del algoritmo de las redes sociales (Nøding).

El primer problema al que lleva esta situación es que la presencia en redes ha de ser constante para que al autor le resulte rentable: en el documental Stripped (Kellet y Schroeder) Stephan Pastis habla sobre la popularidad en Internet: «para ser famoso en la actualidad no puedes 
ser famoso 'y ya está' hay que ser famoso a través de numerosos canales» (Stripped 1:02:23). Mantenerse activo en redes sociales y proveer un feed constante es la mejor manera de alcanzar al público potencial. En segundo lugar, la gamificación de las redes sociales le da crédito a la persona que comparte, no solo a la que lo crea, lo que fomenta que muchos usuarios dejen de «retwittear» para «repostear», en ocasiones incluso recortando la firma de las obras originales (Dale). En España quizá uno de los casos más sonados sea el de la popular página de memes Cabronazi, acusada durante años de subir contenido sin atribuir la autoría (Cantó). En tercer lugar, como señala Allison (Dale), para muchas personas Internet acaba en sus redes sociales y tienen mucha menos predisposición a salir de ellas. Aunque autores como Matt Inman (The Oatmeal) señalan lo beneficioso de que los lectores difundan y viralicen el contenido al repostearlo en sitios web como Reddit (Stripped 1:00:15) hay otros que se han mantenido escépticos respecto a los beneficios de esta difusión frente a la tradicional lectura de las tiras en las páginas web (Dale). Esta pérdida de autonomía y control también ha dificultado la monetización de las creaciones para sus autores, recurriendo frecuentemente a plataformas de micromecenazgo como Patreon o a la venta de merchandising.

Estas nuevas dinámicas de difusión tienen una consecuencia sobre la creación de los webcómics. La facilidad para la viralidad de los memes lleva a muchos autores a incorporar este tema en sus propias viñetas online, incluyendo las «rage-faces» o referencias a otros memes populares en su obra, a pesar de que, como concluye Thoss, estos corren el riesgo de alcanzar su límite cuando la tematización y el conocimiento de las referencias son todo su contenido (565). Como Glaser analiza, en la era de la «recepción memética» la meta-referencialidad en un webcómic ya no se refiere solo a la ruptura del cuarto muro o a referenciar la propia condición del webcómic frente al cómic tradicional y sus elementos expresivos, sino que temáticamente también engloba la reciprocidad entre el autor y los comentarios o las dinámicas asociadas a la viralidad y al uso del webcómic como meme.
Por tanto, el autor se ve obligado a crear la obra con la conciencia de que el lector se percibe como un potencial co-autor que se incrustará en el contenido, bien compartiéndolo fuera del contexto original en el que fue publicado o directamente modificándolo para que este represente sus circunstancias personales. Algunos autores como Alex Norris (Webcomic's name) Shen (Owl Turd Comix) o Sarah Andersen (Sarah's Scribbles) apelan de forma activa a este sentimiento de identificación que en redes se organiza bajo la etiqueta de \#lotípico ${ }^{5}$. Otro escenario son los autores que optan por un estilo que invita al remix y la difusión, como es el caso de Dinosaur Comics (Ryan North, 2003), el cual utiliza una plantilla fija de personajes cuyos diálogos pueden ser modificados. Otros como Deep Dark Fears (Frank Krause, 2014) sacan partido de la creación colectiva dibujando los miedos que sus lectores guionizan y le envían a través de las redes sociales.

A continuación, utilizando el modelo para el análisis de la capacidad memética de un artefacto propuesto por Shifman, se desgranarán los elementos de una tira ampliamente utilizada en redes como meme en los últimos años: On Fire (K.C. Green 2013). El objetivo es comprender mejor el proceso mediante el cual el lenguaje del webcómic se vuelve maleable en manos de estos nuevos co-autores que lo alteran hasta hacerlo un meme.

\section{Memes y viñetas: On fire}

On Fire es una página publicada por K.C. Green el 9 de enero de 2013, parte de su webcómic Gun show (Imagen 1). El cómic, aunque no mantiene una trama, sí cuenta con algunos personajes recurrentes (entre ellos, el perro que aparece en $O n$ Fire).

Volviendo al uso de las dimensiones a la hora de analizar la capacidad memética de un artefacto (contenido, forma y posicionamiento) y utilizando la metodología que aplica Shifman (Shifman, Defining Internet Memes), se pueden observar tanto los elementos que son

En el original: relatable 


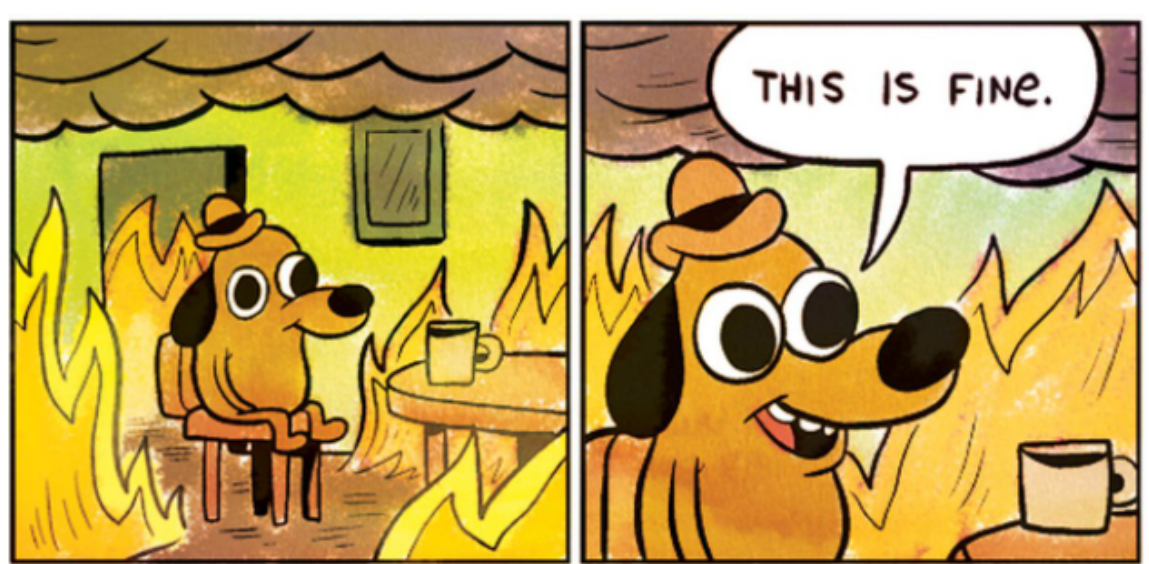

Imagen 1

potencialmente modificados en el proceso de convertirse en un meme como los que mantienen la intención original del autor.

En primer lugar, el contenido del texto es un chiste, el cual se construye con la disyunción (Ramos) entre la primera viñeta y la reacción del personaje en la segunda. La expresión neutral del personaje y su comentario («Todo va bien») contrasta con la situación de estrés en la que se encuentra y que el lector puede ver dibujada en la viñeta (la habitación está en llamas). El cómic, como su autor apunta, está escrito durante una depresión y apela a la necesidad de seguir adelante fingiendo que todo va bien, aunque las cosas no vayan bien (Plante).

Respecto a la forma, el cómic sigue una plantilla de 6 viñetas distribuidas verticalmente en pares. La distribución de la imagen en estas dos primeras viñetas responde a unos criterios de montaje muy relacionados con los planos cinematográficos, ya que la yuxtaposición de ambas será lo que le dé significado a la acción (Gasca y Gubern, 403). La primera viñeta muestra un plano general que inscribe al sujeto en su entorno, mientras que la segunda es un plano medio. Este cambio de escala primero sitúa al personaje en el entorno en el que se desarrolla la acción, mientras que el acercamiento permite al lector apreciar mejor su expresión y acrecienta la sensación de intimidad con él (Gasca y Gubern, 521). El diálogo se plasma a través de un bocadillo cuyo rabillo identifica al personaje que aparece en la escena como el que pronuncia estas palabras. La mise-en-scene es la de un perro ligeramente antropomórfico sentado en una silla de madera en una habitación en llamas mientras bebe de una taza y dice «todo va bien». El encuadre en las siguientes viñetas será el mismo mientras el perro se deshace entre el fuego.

Mientras que la primera dimensión se mantiene prácticamente intacta (un personaje en una situación de estrés fingiendo que no hay ningún problema), la forma del cómic original cambia cuando pasa a compartirse como un meme. La mayoría de las modificaciones en la forma van dirigidas a mejorar la difusión de la imagen (por ejemplo, al fusionar la primera y la segunda viñeta de manera que el diálogo del personaje se incruste en el

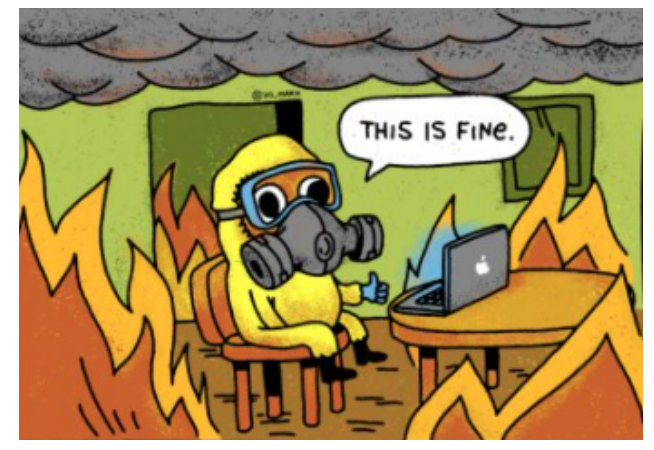

Imagen 2

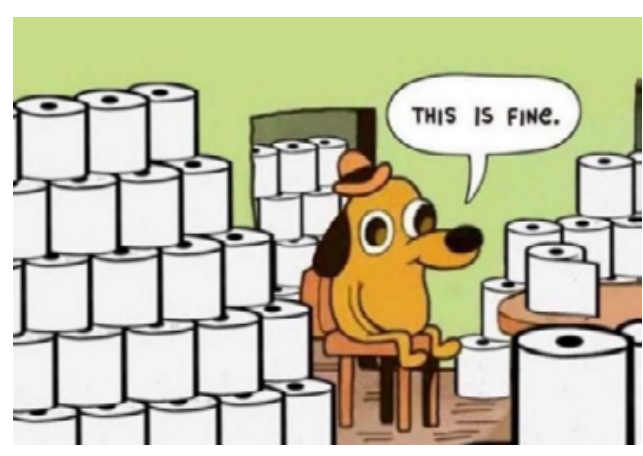

Imagen 3

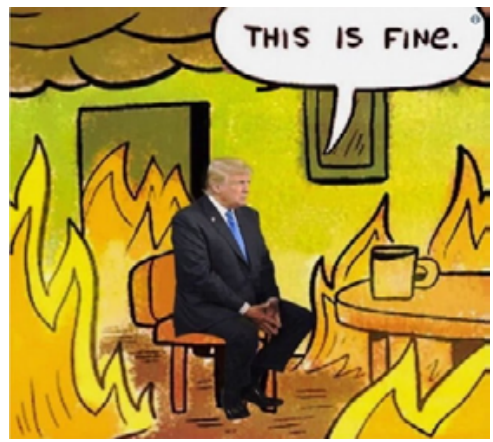

Imagen 4 
plano general) y, como Shifman observa (48), las copias tienden a parecerse más entre ellas que al contenido original. Es el caso de la imagen 2, en la que el contenido mantiene el chiste del cómic y además añade otros elementos: el teletrabajo y la pandemia del Covid-19 durante el año 2020.

Algo parecido ocurre en la imagen 3; el chiste sigue siendo la disyunción entre lo que se ve y el diálogo del personaje, pero las llamas han sido sustituidas por papel higiénico, también en referencia a las primeras semanas del confinamiento por el Covid-19.

Una tercera modificación en la forma es la sustitución del personaje original del cómic por otro diferente. Es el ejemplo de la imagen 4, en la que el perro pasa a ser el expresidente de los Estados Unidos, Donald Trump.

La tercera dimensión, el posicionamiento, es probablemente la más interesante en la mayoría de los casos. La participación, responde a KC Green como autor de webcómics creando un producto para sus lectores mientras que el tono es humorístico, a pesar de que el tema sea un problema serio personal del autor. En tercer lugar, de las seis funciones comunicativas contempladas por Jakobson, en esta página se pueden observar la emotiva, la poética y la referencial: el autor comparte unos sentimientos respecto a una situación personal, representados de forma metafórica como una habitación en llamas. En los tres ejemplos aquí expuestos la participación ha cambiado: ya no se trata de KC Green y sus circunstancias personales, sino de otros autores (muchas veces anónimos) que se dirigen a un público en otro contexto. En estos ejemplos el tono sigue siendo humorístico y se mantienen las funciones, aunque en este caso las referencias son distintas (la pandemia de Covid-19 o la situación política en Estados Unidos). No obstante, y a pesar de las modificaciones, la idea original del autor (fingir normalidad en una situación de estrés o inconveniente) se mantiene gracias a la rápida identificación que se hace con el cómic original.

Según la definición que Shifman propone para los memes (unidades difundidas constituidas por dimensiones meméticas que no solo se propagan bien, sino que, constituyen grupos de unidades de contenido) (39), no resulta difícil ver que el lenguaje de los cómics actúa como un vector memético que permite mantener el contenido, la forma y el posicionamiento reconocibles en las sucesivas modificaciones. La posición de los personajes, el uso de bocadillos, rótulos, estereotipos y la narración secuencial en base a la yuxtaposición son elementos imprescindibles a la hora de leer un cómic, pero a estos se le añaden las referencias implícitas a la propia condición de webcómic y a sus relaciones con la producción y la recepción (Glaser), como pueden ser la rápida difusión o la interactividad entre autor y lector. On Fire no fue dibujada con la intención de que fuera modificada, pero su estructura la ha convertido en una plantilla en la que cualquiera puede incrustarse.

Un buen ejemplo de esta nueva forma de creación es la de Alex Norris, autor de Webcomic name. Las dimensiones meméticas de este webcómic son el punch final, la estructura de tres viñetas, la simplicidad del dibujo y la meta-referencialidad. El webcómic depende en tanta medida de estos factores que incluso funciona al generarse de forma aleatoria, como bien prueba el generador de tiras desarrollado por una fan y que el propio Alex Norris anima a utilizar. En sus propias palabras: «cualquiera puede ser un artista en internet, el listón nunca ha estado tan bajo» (Glitch Team).

En otras ocasiones las modificaciones ni siquiera son necesarias en tanto la función expresiva provoca reacciones afectivas sobre el contenido del cómic original, tal y como ocurre en los ejemplos que propone Glaser: «esto es muy yo» o «esto es muy típico». No se trata solo de imitar, sino de compartir «como parte de la lógica digital que camina sobre las bases de datos» (Enguita, 169). Es el caso de las tiras de Sarab's Scribbles, populares por su enfoque cómico de situaciones cotidianas. Estas tiras son ampliamente compartidas en redes sociales (la autora tiene más de 3 millones y medio de seguidores en Instagram) y aunque no siempre se modifican, son percibidas como memes al pasar a ser compartidas en las distintas plataformas, como Milner argumenta (289), los usuarios tienen libertad para llamar meme a lo que ellos consideren ya que la reapropiación forma parte de 

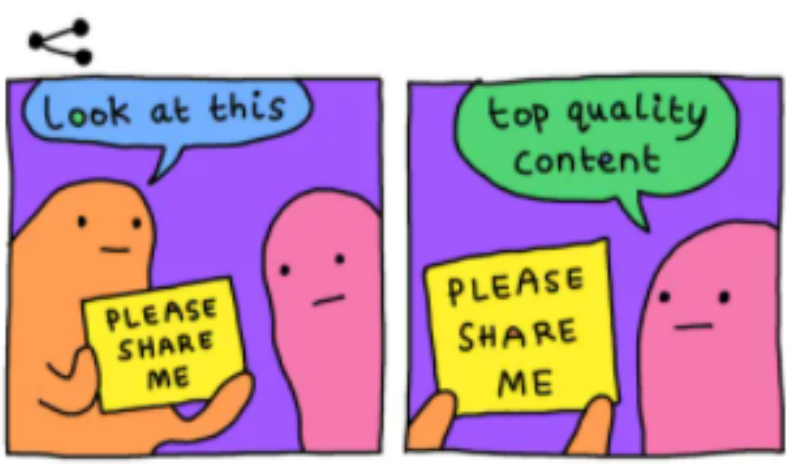

Imagen 5

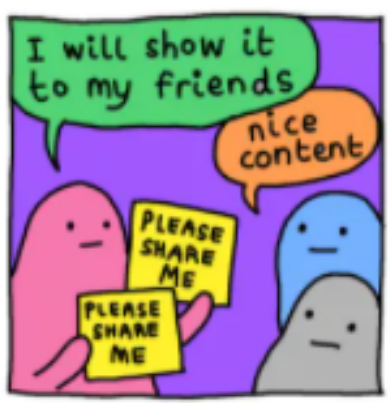

webcomicname.com

mother (Miriam Libicki, 2019) o You're Not Going to Believe What I'm About to Tell You (Matthew Inman, 2019) utilizan el lienzo infinito. Y mientras Cabramatta (Matt Huynh, 2019) o Chuckwagon at the end of the world (Erik Lundy, 2019) juegan con el pacing y la superposición de imágenes, The Eyes (Javi de Castro, 2019) lo hace con pequeñas animaciones camufladas en las viñetas.

$\mathrm{Al}$ igual que estos autores explotan los elementos expresivos propios

la creación del discurso). Al agregar la obra al feed personal mediante el retweet en Twitter, el reblog en Tumblr o el compartir en Facebook, esta pasa a formar parte del relato personal del usuario que la comparte, sin necesidad de dibujarse en ella. El meme, en este caso, no es tanto la tira en sí (que responde más al proceso de viralización previo a la modificación), sino a la lógica de la creación de un contenido cotidiano y la identificación del lector con él (y, por tanto, la necesidad de compartirlo con sus seguidores y amigos) (Imagen 5). ${ }^{6}$

\section{Conclusiones}

Si la popularización de la difusión del contenido en redes sociales recuperó la tira cómica autoconclusiva, la recepción mimética añade una serie de nuevas características a los webcómics que no deben percibirse necesariamente como algo malo. A pesar de la popularidad de las tiras online que se comparten a través de Instagram, Facebook o Twitter, el webcómic como medio de experimentación artística ha seguido desarrollándose, aunque con muy pocas variaciones a lo largo de los años. Es un fenómeno que se puede ver en las nominaciones a los premios Eisner de 2020, tanto dentro como fuera de la categoría de webcómic: los nominados a mejor historia corta Who gets called an unfit

Imagen 5: Norris, Alex. Please reblog. 29 de Julio de 2016. < https://webcomicname.com/post/148143828199/please-reblog $>$.

del medio online que comenzaron a utilizarse a finales de los años 90, otros autores han hecho lo propio con los elementos asociados a la viralidad y los memes: la autoreferencialidad, el uso de rage-faces y en general la explotación de esa cultura vernacular digital que, tal y como ocurre con los GIF o con el lienzo infinito, es también exclusiva de la cultura participativa mediada. Si bien no se puede predecir cuál será el futuro del medio, es interesante prestar atención a estas nuevas formas de creación fundamentadas en la difusión, la modificación y la meta-referencialidad. Se plantean preguntas tales como cuáles son las vías de financiación posibles para estos autores, el debate respecto a la autoría en la era de la recepción memética y las nuevas barreras que surgen a los autores en este entorno cuya democracia ha sido probada cuestionable. Aunque la «memetización» de los webcómics ha sido una vía para ganar popularidad y tener la libertad de crear otro tipo de contenido (como es el caso de The Oatmeal), para otros el proceso ha sido el contrario, perjudicando gravemente sus carreras, tal y como le ocurre a Matt Furie, creador de Pepe the Frog (Jones). Y es que, lejos de ser inofensivas imágenes circulando por redes sociales, los memes han jugado un importante papel en la transmisión de mensajes ideológicos en las redes. Como plantea Nagle (25):

«Lo que hoy llamamos alt-right nunca habría conseguido tener una conexión con el mainstream y con una nueva generación de gente joven si solo apareciese en la forma de largos tratados 
en blogs minoritarios. Fue la cultura basada en la imagen y el humor de la fábrica de memes irreverentes 4chan y luego 8chan la que dio a la alt-right una energía juvenil con su transgresión»

Para muchos autores, la única forma de que sus creaciones lleguen al público es adaptarlas a los nuevos formatos de Instagram o Twitter, aun corriendo el riesgo de que estas puedan ser modificadas o robadas y con las limitaciones artísticas que esta decisión conlleva. Sin duda, abre un debate sobre la forma en la que se consume el contenido en Internet y si esta es ética o responsable. Al fin y al cabo: ¿se mueven los gifs de una viñeta cuando nadie la está leyendo?

\section{Bibliografía}

Adventures into digital comics. Dir. Sebastien Dumesnil. Top Two Three Films. 2006.

Alter, Adam. «Tech Bigwigs Know How Addictive Their Products Are. Why Don't the Rest of Us?» Wired (2017). 17 de Mar de 2021. <www.wired. com/2017/03/irresistible-the-rise-of-addictive-technology-and-the-business-of-keeping-us-hooked/>.

Campbell, Maria E. «Inking Over the Glass Ceiling: The Marginalization of Female Creators and Consumers in Comics.» ObioLINK Electronic Theses and Dissertations Center (2015). Tesis.

Campbell, T. The History of Webcomics. Texas: Antartic Press, 2006.

Cantó, Pablo. «Qué es Cabronazi y qué nos enseña de la copia de contenidos en Internet». El País Verne (2018). 17 de Ene de 2021. <verne.elpais.com/verne/2018/08/10/articulo/1533900090_524140.html>. Casacuberta, David. Creación colectiva: en Internet el creador es el público. Barcelona: Gedisa Editorial, 2003.

Cruz, Eduardo Fernando Aguado, Luis Gabriel Arango Pinto y Verónica Ochoa López. «Hacia un modelo de análisis de memes basados en imágenes macro». Viator. Revista cientifica de comunicación desde los bordes, 6 2018, pp. $48-86$.
Dale, Brady. «The Changing Internet Through Webcomics.» Observer (2015). 17 de Ene de 2021. <observer. com/2015/11/webcomics-and-the-changing-web/>.

Dawkins, Richard. El gen egoísta. Barcelona: Salvat, 1976.

Enguita, Adrián Alonso. «El meme en su temporalidad». Eikasia:revista de filosofía, 82, 2018, pp. 159-177.

Feels Good Man. Dir. Arthur Jones. Ready Fictions. 2020.

Frattini, Eric y Oscar Palmer. Guía básica del cómic. Madrid: Nuer, 1999.

Gallo, Carmine. «Dilbert creator Scott Adams reveals the simple formula that will double your odds of success». 23 de Oct de 2013. Forbes. <www.forbes.com/ sites/carminegallo/2013/10/23/dilbert-creatorscott-adams-reveals-the-simple-formula-that-willdouble-your-odds-of-success/\#46b56c0d1a3e>.

Garrity, Shaenon. «One of those things». 18 de Abr de 2013. The Comics Journal. 17 de Ene de 2021. <www. tcj.com/one-of-those-things/>.

— «The History of Webcomics». 15 de Jul de 2011. The Comics Journal. 17 de Ene de 2021. <www.tcj.com/ the-history-of-webcomics/>.

Gasca, Luis y Román Gubern. El discurso del cómic. Madrid: Cátedra, 1988.

Glaser, Tim. «oh no - this comic is literally me: Webcomics im Zeitalter ihrer memetischen Rezeption». Closure. Kieler e-Journal für Comicforschung, 4.5, 2018, pp. 118-133.

Glitch Team. «An Addictive Generator For 'Oh No' Comics? Oh Yes!». 02 de Abr de 2019. Apps We Love. 17 de Ene de 2021. <blog.glitch.com/post/createyour-own-webcomicname-oh-no>.

Groth, Gary. «McCloud Cuckoo-Land». The Comics Journal, 232, 2001, 32.

K.C. Green. «On Fire.» 09 de Ene de 2013. Gun Show. 17 de Ene de 2021.

Knobel, Michele y Colin Lankshear. «Online memes, affinities, and cultural production». A new literacies sampler, 29, 2007, pp. 199-227.

Kukkonen, Karin. «Web Comics». John Hopkins Guide to Digital Media. Ed. M.Ryan y B.Robertson. Baltimore: John Hopkins University Press, 2014, 521-524. 
Luiz, Lúcio. «Fffffffuuuuuuuuuuuu: o fenômeno das rage comics e sua relação com os quadrinhos». XXXV Congresso Brasileiro de Ciências da Comunicação (2012).

Milner, Ryan M. The world made meme: Discourse and identity in participatory media. University of Kansas, 2012. Tesis.

Nagle, Angela. Muerte a los normies: las guerras culturales en internet que han dado lugar al ascenso de Trump y la altright. Tarragona: Orciny Press, 2018.

Nøding, Håvard Knutsen. The tools of Webcomics: The «infinite canvas» and other innovations. University of Oslo, 2020. Tesis.

Norris, Alex. Please reblog. 29 de Julio de 2016. < https:/ / webcomicname.com/post/148143828199/pleasereblog $>$.

Plante, Chris. «This Is Fine creator explains the timelessness of his meme». 05 de Mayo de 2016. The Verge. 17 de Ene de 2021. <www.theverge.com/2016/5/5/11592622/ this-is-fine-meme-comic $>$.

Ramos, Rafael Núñez. «Semiótica del mensaje humorístico.» Gallardo, Ed. Miguel Angel Garrido. Teoría semiótica : lenguajes y textos hispánicos : volumen I de las actas del Congreso Internacional sobre Semiótica e Hispanismo celebrado en Madrid en los diás del 20 al 25 de junio de 1983. CSIC, 1984, pp. 269-276.

Samela, Gabriela. «Internet y la repetición de lo igual». AVATARES de la comunicación y la cultura, 10, 2015, pp. 1-15.

Shifman, Limor. «Defining Internet Memes.» Shifman, Limor. Memes in Digital Culture. EEUU: MIT Press, 2014, pp. 38-54.
- Memes in digital culture. EEUU: MIT Press, 2014.

Sibila, Paula. La intimidad como espectáculo. Buenos Aires: FCE, 2012.

Stripped. Dirs. Dave Kellet y Frederik Schroeder. Sequential Films. 2014.

Thoss, Jeff. «“This Strip Doesn't Have a Fourth Wall” Webcomics and the Metareferential Turn». The Metareferential Turn in Contemporary Arts and Media. Ed. Werner Wolf y Katharina Bantleon. Amsterdam: Rodopi, 2011, pp. 5521-568.

Wilde, Lukas. «Distinguishing Mediality: The Problem of Identifying Forms and Features of Digital Comics». Networking Knowledge: Journal of the MeCCSA Postgraduate Network, 8.4, 2015, pp. 1-14, https://doi. org/10.31165/nk.2015.84.386.

Xerexes, Xavier. «From Gurl to Ignatz: Tracy White talks Traced». 29 de Sep de 2008.

Yarbrough, Beau. «A talent deserving of wider recognition: 'Justine Shaw of Nowhere Girl'». 07 de Jul de 2003. CBR. 17 de Ene de 2021. <https://www. cbr.com/a-talent-deserving-of-wider-recognitionjustine-shaw-of-nowhere-girl/>.

Zabel, Joe. «Making Lightning: an interview with Scott McCloud». 21 de Jun de 2006. The Webcomics Examiner. 17 de Ene de 2021. <https://web.archive.org/ web/20061111093722/http://webcomicsreview. $\mathrm{com} /$ ? $=151 \&$ page $=1>$. 